\title{
Sensory and microbiological quality of yogurt drinks with prebiotics and probiotics
}

\author{
L. C. Allgeyer, ${ }^{*}$ M. J. Miller, ${ }^{*} \dagger$ and S.-Y. Lee ${ }^{* 1}$ \\ *Department of Food Science and Human Nutrition, and \\ †Division of Nutritional Sciences, University of Illinois, Urbana 61801
}

\begin{abstract}
The popularity of dairy products fortified with prebiotics and probiotics continues to increase as consumers desire flavorful foods that will fulfill their health needs. Our objectives were to assess the sensory profile of drinkable yogurts made with prebiotics and probiotics and to determine the viability of the probiotics in the yogurt drink over the duration of storage. Thirteen trained descriptive panelists evaluated 10 yogurt drinks on a 16-point category scale. Three selected prebiotics, soluble corn fiber, polydextrose, and chicory inulin, were each present individually at an amount to claim an excellent source of fiber ( $5 \mathrm{~g}$ of fiber/serving) or a good source of fiber ( $2.5 \mathrm{~g}$ of fiber/serving) in 6 different yogurt drinks. Three additional yogurt drinks contained 5 $\mathrm{g}$ of each of the separate prebiotics along with a mixture of the selected probiotics (Bifidobacterium lactis $\mathrm{Bb}-12$ and Lactobacillus acidophilus LA-5). A control sample with no prebiotics or probiotics was also included in the experimental design. Data were analyzed by ANOVA, Fisher's least significant difference, and principal component analysis. Survival of the probiotics in the yogurt drinks during a 30-d refrigerated storage period was also analyzed. Results showed that clover honey aroma, buttermilk aroma, butter aroma, sweetness, sourness, chalky mouthfeel, and viscosity were identified as significant attributes in the yogurt drinks. Total variance explained by the principal component analysis biplot of factors 1 and 2 was $65 \%$, which showed yogurt drinks with soluble corn fiber and inulin varying by the sweet versus sour attributes and yogurt drinks with polydextrose varying by the mouthfeel attributes. The viability study determined a 2- to 3-log decrease in the survival of probiotics in all of the yogurt treatments during a $30-d$ refrigerated storage period. Based on the results of the current study, only the polydextrose treatment
\end{abstract}

Received July 22, 2009.

Accepted June 7, 2010.

${ }^{1}$ Corresponding author: soolee@illinois.edu would be an acceptable vehicle to deliver the probiotic health effects at the end of the 30-d storage period.

Key words: sensory, yogurt, probiotic, prebiotic

\section{INTRODUCTION}

Yogurt is among the most common dairy products consumed around the world, and its sensory attributes have a large effect on consumer acceptability (Saint-Eve et al., 2006). Drinkable yogurt, categorized as stirred yogurt with a low viscosity, is a growing area of interest based on its convenience, portability, and ability to deliver all of the health and nutritional benefits of stirred or set yogurt (Eder, 2003; Thompson et al., 2007). The low viscosity is obtained through high agitation, which breaks the coagulum after the fermentation period, before the product is bottled and refrigerated (Tamime and Robinson, 1985). The Food and Drug Administration (FDA, 2008) standard of identity for yogurt drinks specifies $>8.25 \%$ milk solids-not-fat and fat levels to satisfy nonfat yogurt $(<0.5 \%)$, low-fat yogurt $(2 \%)$, or yogurt $(>3.25 \%)$ before the addition of other ingredients (Chandan et al., 2006). A typical low-fat yogurt drink available in the United States has 8.0 to $9.5 \%$ milk solids-not-fat and contains 5 to $12 \%$ added sugar. Yogurt drink $\mathrm{pH}$ varies from 4.0 to 4.5 (Tamime and Robinson, 1985; Chandan et al., 2006). In regard to flavor, strawberry is the most popular yogurt flavor followed by other fruit flavors (Thompson et al., 2007). Currently, few nonflavored yogurt drinks are available in the United States.

As the popularity of yogurt products continues to grow, manufacturers are continuously investigating value-added ingredients such as prebiotics and probiotics to entice health-conscious consumers. Probiotics are referred to as "live microorganisms, which when administered in adequate amounts confer a health benefit on the host" (FAO/WHO, 2001). Lactobacillus and Bifidobacteria species are the most common types of probiotics. Prebiotics are classified as "non-digestible food ingredients that beneficially affect the host by selectively stimulating the growth and/or activity of one 
or a limited number of bacteria in the colon, and thus improve host health" (Gibson and Roberfroid, 1995). Currently, the most widely accepted prebiotics include fructooligosaccharides and galactooligosaccharides (ISAPP, 2009). When prebiotics are combined with probiotics, their relationship is classified as synbiotic. This combination can improve the survival rate of the probiotics and provide additional health benefits to the host (Collins and Gibson, 1999).

Sensory analysis of yogurt drinks with prebiotics and probiotics is needed for manufacturers looking to incorporate the healthful ingredients into their products. Inclusion of probiotics has been shown to not significantly alter the sensory properties of dairy products (Hekmat and Reid, 2006); however, prebiotics such as inulin have the ability to be a fat substitute, bulking agent, low-calorie sweetener, and texture modifier when added to yogurt, therefore potentially altering the sensory perception of the product (Guggisberg et al., 2009). The growing number of possible prebiotics needs to be evaluated for their sensory effect before commercial inclusion. Previous studies determined that selected probiotics do not alter the sensory profile of prebiotic-containing yogurt (Hekmat and Reid, 2006; Kailasapathy, 2006). However, it is unknown if this is true for all probiotics and whether this applies to prebiotic-containing yogurt drinks.

The viability of the probiotic strains in the yogurt drink matrix is another area of interest when investigating the quality of yogurt drinks with novel prebiotics and probiotics. Currently, there is no standard of identity for probiotics (Sanders et al., 2007). The suitable level of viable probiotic cells remains obscure with no current regulatory requirements. Additionally, the minimum dose for a given health benefit likely varies for individual probiotics (Sanders et al., 2007). Regardless, it has been suggested that foods with probiotics should contain from $10^{6}$ to $10^{8}$ cells/g (not including starter culture) and remain at this level for the duration of the product's shelf life (Fonden et al., 2000). To effectively deliver the optimal level of bacterial cells to the consumer, it is critical that viable cell counts are assessed and appropriate measures are taken to ensure the survival of the bacteria.

The main objectives of this study were (1) to produce an appealing vanilla control yogurt drink similar to commercial products that will serve as a basis of comparison for yogurt drinks with added prebiotics and probiotic cultures, (2) to determine the effects of prebiotics and probiotics added to the model yogurt formulation on the flavor, aroma, and texture properties using descriptive analysis, and (3) to investigate the survival of the probiotic cultures as affected by the prebiotics tested in the yogurt drinks with prebiotics over a 30 -d refrigerated storage period.

\section{MATERIALS AND METHODS}

\section{Development of Yogurt Drink}

For the yogurt drink process used in this study, pasteurized and homogenized skim milk (Schnucks Skim Milk, Schnucks Market Inc., St. Louis, MO) was used as the main dairy ingredient. During the first stage of formulation, sucrose $(\mathrm{C}+\mathrm{H}$ Pure Cane Sugar Granulated White, $\mathrm{C}+\mathrm{H}$ Sugar Company Inc., Crockett, CA) was added to the milk at a relatively low level of $5 \%$ (5-12\% recommended) because inclusion of prebiotics has been shown to contribute to the sweetness of yogurts (Guggisberg et al., 2009). The milk and sugar were then heated and agitated (ThermoMix TM 21, Vorwerk USA Co., Altamonte Spring, FL) at $70^{\circ} \mathrm{C}$ for 20 min to mimic a pasteurization step. In the yogurt drinks with prebiotic inclusion at a low or high level, the prebiotic was incorporated after $10 \mathrm{~min}$ of heating to ensure full dispersion. This time and temperature combination was selected based on process stability data available for Litesse polydextrose (Litesse II Super Improved Polydextrose Fcc, Danisco USA Inc., Ardsley, NY; Beer et al., 1991), which allowed us to use a milder heat treatment than the typical heat treatment applied in yogurt manufacture of $85^{\circ} \mathrm{C}$ for $30 \mathrm{~min}$. After the pasteurization step, the yogurt drink was cooled in the freezer $\left(0-5^{\circ} \mathrm{C}\right)$ until a temperature of $42^{\circ} \mathrm{C}$ was reached and the drink was then ready to be inoculated with starter cultures at a level of $0.02 \%$. When the probiotics Bifidobacterium lactis $\mathrm{Bb}-12$ and Lactobacillus acidophilus LA-5 (BB-12 and LA-5 Nutrish a/B probiotic mix, Chr. Hansen Inc., Milwaukee, WI) were included in the formulation, the level of starter cultures was reduced to $0.01 \%$. Both starter cultures and probiotics were initially present as frozen pellets and were first thawed and then prepared as a $10 \%$ dilution in water before inoculation. The procedures for preparing and adding the probiotics were determined based on manufacturer recommendations. Probiotics were present as a 50:50 ratio mix of Bb-12 and LA-5 and were added at the same time of the starter cultures. The starter cultures were a mix of Streptococcus thermophilus and Lactobacillus delbrueckii ssp. bulgaricus (F-DVS YC-X11, Yo-Flex, Chr. Hansen Inc.). After inoculation, the yogurt drink was then agitated for $30 \mathrm{~min}$ to disperse the cultures while maintaining a temperature of $42^{\circ} \mathrm{C}$. The product was then placed in an incubator (Isotemp Standard Incubator 637D, Fisher Scientific, Pittsburgh, PA) for fermentation at $42^{\circ} \mathrm{C}$ for around 5 to $6 \mathrm{~h}$ until $\mathrm{pH} 4.3$ 
Table 1. Experimental design of yogurt sensory study for 10 total treatments

\begin{tabular}{|c|c|c|c|c|c|c|c|c|c|c|}
\hline \multirow[b]{2}{*}{ Item } & \multirow[b]{2}{*}{ Control } & \multicolumn{6}{|c|}{ Without probiotics } & \multicolumn{3}{|c|}{ With probiotics (Pro) ${ }^{1}$} \\
\hline & & Low & High & Low & High & Low & High & $\begin{array}{c}\text { PDX } \\
+ \text { Pro }\end{array}$ & $\begin{array}{c}\text { SCF } \\
+ \text { Pro }\end{array}$ & $\begin{array}{l}\begin{array}{l}\text { Inulin } \\
+ \text { Pro }\end{array} \\
\text { High }\end{array}$ \\
\hline Prebiotics $^{2}(\%)$ & 0 & 1.23 & 2.45 & 1.70 & 3.34 & 1.24 & 2.48 & 2.45 & 3.34 & 2.48 \\
\hline
\end{tabular}

${ }^{1}$ Probiotics were Lactobacillus acidophilus LA-5 and Bifidobacterium lactis Bb-12 (Chr. Hansen, Milwaukee, WI).

${ }^{2}$ Amounts of prebiotics used were dependent on the percentage of fiber in the prebiotic to allow for the claims of a good source of fiber (2.5 $\mathrm{g} /$ serving) or an excellent source of fiber ( $5 \mathrm{~g} /$ serving; FDA, 2008) for a 240-mL serving size.

to 4.4 was obtained. The $\mathrm{pH}$ was initially measured at $5 \mathrm{~h}$ of fermentation and every 20 min thereafter until the desired $\mathrm{pH}$ was reached. Fermentation time varied within yogurt drink replicates, suggesting that prebiotic or probiotic addition was not a significant factor for determining fermentation time. After fermentation, the coagulum was broken through an additional agitation step at $42^{\circ} \mathrm{C}$ for $30 \mathrm{~min}$. During this time, powdered natural and artificial vanilla flavor (Natural \& Artificial Vanilla Flavor Powder, lot\# S090833, Flavors of North America-FONA, Geneva, IL) was added to the yogurt drink at a level of $0.20 \%$ to provide an acceptable consumer product for consumption. After the final agitation step, the yogurt was poured into sanitized Mason jars (1 L, Hearthmark Inc., Muncie, IN) and refrigerated for at least $24 \mathrm{~h}$ before serving. To determine specific amounts of the ingredients, a serving size of 240 $\mathrm{mL}$ was assumed for the product.

\section{Experimental Design}

Ten yogurt drink treatments were included in the study design. Table 1 depicts the different yogurt drinks by percentage of prebiotic included in the formulation. Three prebiotics were used in this study, polydextrose (Litesse II Super Improved Polydextrose FCC, Danisco USA Inc., Ardsley, NY), chicory inulin (Beneo GR, Orafti Active Food Ingredients, Tienen, Belgium), and soluble corn fiber (Promitor Soluble Corn Fiber, Tate \& Lyle, Decatur, IL). Each prebiotic was present at a low level and a high level in the yogurt drink based on the amount of fiber it contained. The low level corresponded to the amount required to claim the product as a good source of fiber $(2.5 \mathrm{~g} /$ serving $)$ and the high level to that required to claim the product as an excellent source of fiber ( $5 \mathrm{~g} /$ serving) as determined by the US Food and Drug Administration (FDA, 2008). Three of the 10 yogurt drinks contained the high level of the prebiotics along with a mixture of the selected probiotics, $0.02 \%$ of Bifidobacterium lactis Bb-12 and Lactobacillus acidophilus LA-5. A control yogurt drink was also present in the design; it contained no prebiotics or probiotics. A yogurt drink containing only probiotics was not included in the study because numerous studies have shown no sensory effect of probiotic inclusion alone in yogurt (Atunes et al., 2005; Hekmat and Reid, 2006).

\section{Subjects for Descriptive Panel}

Thirteen panelists (4 male, 9 female, aged 21-29 yr) participated on the panel. Subjects were initially recruited based on interest, availability, nonsmoking status, and lack of food allergies.

Following recruitment, subjects were further screened with a basic tastes test where they were asked to identify the taste associated with several solutions at low concentrations. Solutions were served in 29.6-mL plastic cups with lids (Solo Cup Company, Urbana, IL). Sucrose, citric acid, sodium chloride, and caffeine were added at a low level to water to be identified as sweet $(0.70 \%$ sucrose solution $)$, sour $(0.05 \%$ citric acid solution), salty $(0.10 \% \mathrm{NaCl}$ solution), or bitter $(0.02 \%$ caffeine solution) by the panelists (Mojet et al., 2001). Six solutions were presented, with citric acid being presented twice and spring water once as a blank.

The prospective panelists were further screened by 6-n-propyl-2-thiouracil (PROP)-impregnated filter paper prepared according to Zhao et al. (2003) and asked if they were able to perceive a bitter taste when placing the paper on their tongue. The PROP paper was served in 29.6-mL plastic cups with lids (Solo Cup Company). Subjects who identified 3 out of the 6 basic taste solutions correctly and who perceived the bitter taste associated with the PROP test were further asked to participate on the panel.

\section{Panel Training}

The 13 panelists selected for the descriptive panel participated in twenty $1-\mathrm{h}$ training sessions. The first 5 sessions focused on term generation and introduction 
to references. During the following weeks, the panel refined and defined the attributes they generated and practiced scaling references in relation to the intensity of the attribute within the yogurt products they tasted. The 10 yogurt drinks in the experimental design (Table 1) were presented and evaluated an equal number of times throughout the training process. Panelists also developed a rinsing protocol to eliminate any carryover effect while evaluating the yogurt. This consisted of carbonated water (Schweppes Tonic Water, Plano, TX) followed by cool spring water (Absopure, Plymouth, MI). During the $15 \mathrm{~d}$ of training, the panel came up with 12 attributes that most consistently described the yogurt products (Table 2) and practiced evaluating the products in a roundtable setting to facilitate discussion. Subsequently, they moved on to individual booth training for $4 \mathrm{~d}$.

\section{Sample Evaluation}

Panelists completed two 1-h final evaluations on separate days, in which they evaluated each yogurt drink product presented in the design (Table 1) in duplicate. The panelists sat around a table and refamiliarized themselves with the references and the reference intensities (Table 2). The panelists then went into individual booths equipped with Compusense Five data acquisition system (Version 4.8, Compusense, Guelph, Ontario, Canada) and evaluated the 10 yogurt samples. Each sample was served monadically to keep the temperature constant $\left(0-5^{\circ} \mathrm{C}\right)$. All samples were given to panelists in 59.1-mL cups (Solo Cup Company) labeled with a random 3-digit code, and products were presented in a randomized order across panelists. Panelists were instructed to rinse before tasting each sample. To minimize fatigue, there was a 10-min break in between sample 5 and 6 during each evaluation hour. Evaluation was conducted under incandescent lighting and at room temperature $\left(\sim 24^{\circ} \mathrm{C}\right)$. Each attribute was evaluated on a 16-point category scale that ranged from 0 to 15 .

\section{Assessing Viability of Commercial Probiotic Cultures in Yogurt Drink}

Five yogurt drinks were tested for viable cell counts of B. lactis Bb-12 and Lb. acidophilus LA-5. The yogurt drinks included in the viability study were a control (no pre- or probiotics), control with only probiotics, polydextrose ( $5 \mathrm{~g}$ of fiber) with probiotics, soluble corn fiber (5 $\mathrm{g}$ of fiber) with probiotics, and inulin (5 $\mathrm{g}$ of fiber) with probiotics. Yogurt drinks were stored in a refrigerator at $4^{\circ} \mathrm{C}$. The 5 yogurt samples were plated on d 1, 10, 20, and 30 in triplicate for each probiotic. The method used for selective enumeration of viable $L$. acidophilus LA-5 and B. lactis Bb-12 cells was obtained from Chr. Hansen (P-10 and P-12 technical bulletin). To determine the survival of the Lb. acidophilus culture, $0.5 \mathrm{~mL}$ of sterilized $0.02 \%$ clindamycin stock solution (Clindamycin $\mathrm{HCl}$, Biomol Research Labs Inc., Plymouth Meeting, PA) was added per liter of deMan, Rogosa, and Sharpe (MRS) agar (Lactobacilli MRS Broth, Hardy Diagnostics, Santa Maria, CA; and agar granulated, Fisher Scientific, Fair Lawn, NJ). Bifidobacteria were selectively grown on MRS agar that contained $5 \mathrm{~mL}$ of $0.01 \%$ dicloxacillin stock solution (Dicloxacillin sodium salt, MP Biomedicals LLC, Solon, OH), $10 \mathrm{~mL}$ of $11 \%$ lithium chloride stock solution (Acros Organics, Morris Plains, NJ), and $5 \mathrm{~mL}$ of $10 \%$ cysteine hydrochloride stock solution (L-cysteine hydrochloride hydrate, Acros Organics) per liter of medium. The spiral plate (Eddy Jet-Spiral Plater, IUL Instruments, Barcelona, Spain) technique was used for enumeration of both probiotics. All plates were incubated anaerobically $\left(90 \% \mathrm{~N}_{2}, 5 \%\right.$ $\mathrm{H}_{2}$, and $\left.5 \% \mathrm{CO}_{2}\right)$ at $37^{\circ} \mathrm{C}$ for $3 \mathrm{~d}$ before colonies were enumerated.

\section{Statistical Analyses}

The data were analyzed using ANOVA by the GLM procedure and the mean separation test by the Fisher's least significant difference (LSD) with a $95 \%$ confidence level (SAS version 9.1, SAS Institute Inc., Cary, NC). Principal component analysis (PCA) biplots were constructed using XLSTAT version 2008 (Addinsoft USA, New York, NY).

\section{RESULTS AND DISCUSSION}

\section{Descriptive Analysis}

A total of 7 out of the 12 attributes generated by the panel were found to be significantly different $(P$ $<0.05)$ across the yogurt drinks. These 7 attributes included clover honey aroma, buttermilk aroma, butter aroma, sweetness, sourness, chalky mouthfeel, and viscous mouthfeel (Table 3). Panelists were a significant source of variation $(P<0.05)$ for all attributes. This could be caused by scaling differences among the panelists, which is typically seen in descriptive analysis panels. Replication by sample and panelist by sample interactions were not significant sources of variation for any of the attributes, indicating that the panelists were consistent in their evaluations, and the panel as a whole agreed.

Specific product differences from the descriptive panel can be identified in Table 4. For chalky mouthfeel, only one of the prebiotic beverages (inulin low) had a significantly greater chalky mouthfeel compared with the 
Table 2. Descriptive terms with definitions and references with reference preparation and intensity

\begin{tabular}{|c|c|c|c|c|c|}
\hline Modality & Term & Definition & Reference preparation & Reference product & $\begin{array}{l}\text { Reference } \\
\text { intensity }^{1}\end{array}$ \\
\hline \multirow[t]{4}{*}{ Aroma } & Vanilla & $\begin{array}{l}\text { The aroma of diluted } \\
\text { vanilla extract }\end{array}$ & $\begin{array}{l}1 \mathrm{~g} \text { of vanilla extract in } 300 \mathrm{~mL} \text { of } \\
\text { water [5 g into } 147.87-\mathrm{mL} \text { (5-oz.) cup] }\end{array}$ & $\begin{array}{l}\text { Durkee Pure Vanilla Extract (ACH } \\
\text { Food Companies Inc., Memphis, TN) }\end{array}$ & 10 \\
\hline & Clover honey & $\begin{array}{l}\text { The sweet aroma of } \\
\text { diluted clover honey }\end{array}$ & $\begin{array}{l}0.85 \mathrm{~g} \text { of honey in } 30 \mathrm{~mL} \text { of water } \\
\text { [place in } 147.87-\mathrm{mL}(5-\mathrm{oz} .) \text { cup] }\end{array}$ & $\begin{array}{l}\text { Great Lakes Clover Honey } \\
\text { (Great Lakes, Onsted, MI) }\end{array}$ & 11 \\
\hline & Buttermilk & $\begin{array}{l}\text { The sour aroma of } \\
\text { diluted buttermilk }\end{array}$ & $\begin{array}{l}0.88 \mathrm{~g} \text { of buttermilk in } 10 \mathrm{~mL} \text { water } \\
\text { [place in } 147.87-\mathrm{mL}(5-\mathrm{oz} .) \mathrm{cup} \text { ] }\end{array}$ & $\begin{array}{l}\text { Prairie Farms 1\% Buttermilk } \\
\text { (Prairie Farms, Carlinville, IL) }\end{array}$ & 10 \\
\hline & Butter & The aroma of solid butter & $\begin{array}{l}0.3 \mathrm{~g} \text { of solid butter [place in } \\
147.87-\mathrm{mL}(5-\mathrm{oz} .) \text { cup] }\end{array}$ & $\begin{array}{l}\text { Schnucks Butter (Schnucks } \\
\text { Market Inc., St. Louis, MO) }\end{array}$ & 11 \\
\hline Aroma-by-mouth & Vanilla & $\begin{array}{l}\text { The aroma of diluted vanilla } \\
\text { flavoring while in mouth }\end{array}$ & $\begin{array}{l}1.5 \mathrm{~g} \text { of vanilla powder in } 250 \\
\mathrm{~mL} \text { of water }[20 \mathrm{~mL} \text { served } \\
\text { in } 29.57-\mathrm{mL}(1-\mathrm{oz} .) \text { cup }]\end{array}$ & $\begin{array}{l}\text { Natural and Artificial Vanilla Flavor } \\
\text { Powder, Lot\# S090833 (Fona, Geneva, IL) }\end{array}$ & 10 \\
\hline \multirow[t]{4}{*}{ Taste and aftertaste } & Sweet & $\begin{array}{l}\text { The taste of sucrose in solution } \\
\text { while sample is in mouth }\end{array}$ & $\begin{array}{l}6.3 \mathrm{~g} \text { of sugar in } 600 \mathrm{~mL} \text { of water [ } 20 \\
\mathrm{~mL} \text { served in } 29.57-\mathrm{mL}(1-\mathrm{oz} .) \text { cup] }\end{array}$ & $\begin{array}{l}\text { C+H Pure Cane Sugar Granulated White } \\
(\mathrm{C}+\mathrm{H} \text { Sugar Company Inc., Crockett, CA) }\end{array}$ & 9 \\
\hline & Sour & $\begin{array}{l}\text { The taste of citric acid in solution } \\
\text { while sample is in mouth }\end{array}$ & $\begin{array}{l}0.35 \mathrm{~g} \text { of citric acid in } 500 \\
\mathrm{~mL} \text { of water }[20 \mathrm{~mL} \text { served } \\
\text { in } 29.57-\mathrm{mL}(1-\mathrm{oz} .) \text { cup }\end{array}$ & $\begin{array}{l}\text { Anhydrous granular citric acid } \\
\text { (Tate \& Lyle, Decatur, IL) }\end{array}$ & 11 \\
\hline & Sour aftertaste & $\begin{array}{l}\text { The immediate aftertaste of } \\
\text { lactic acid solution after the } \\
\text { sample is expectorated }\end{array}$ & $\begin{array}{l}2 \mathrm{~g} \text { of lactic acid in } 800 \mathrm{~mL} \\
\text { of water [20 mL served in } \\
29.57-\mathrm{mL}(1-\mathrm{oz} .) \text { cup] }\end{array}$ & $\begin{array}{l}88 \% \text { Lactic Acid (LD Carlson } \\
\text { Company, Kent, OH) }\end{array}$ & 11 \\
\hline & Cheese aftertaste & $\begin{array}{l}\text { The instantaneous aftertaste } \\
\text { of ricotta cheese after the } \\
\text { sample is expectorated }\end{array}$ & $\begin{array}{l}1 \text { tsp. of part-skim ricotta cheese } \\
\text { served in } 29.57-\mathrm{mL}(1-\mathrm{oz} .) \text { cup }\end{array}$ & $\begin{array}{l}\text { Schnucks Ricotta Part-Skim Cheese } \\
\text { (Schnucks Market Inc.) }\end{array}$ & 10 \\
\hline \multirow[t]{2}{*}{ Mouthfeel } & Chalky & $\begin{array}{l}\text { The mouthfeel of crushed } \\
\text { calcium carbonate tablets } \\
\text { dispersed in skim milk }\end{array}$ & $\begin{array}{l}25 \text { calcium carbonate tablets ground } \\
\text { in } 250 \mathrm{~mL} \text { of skim milk [ } 20 \mathrm{~mL} \\
\text { served in } 29.57-\mathrm{mL} \text { (1-oz.) cup] }\end{array}$ & $\begin{array}{l}\text { TopCare Antacid Calcium Chewable } \\
\text { Tablets, Extra Strength, Assorted Fruit } \\
\text { (Topco Associates LLC, Skokie, IL) }\end{array}$ & 10 \\
\hline & Viscous & $\begin{array}{l}\text { The instantaneous thickness } \\
\text { of heavy cream in mouth }\end{array}$ & $\begin{array}{l}\text { Heavy cream }[20 \mathrm{~mL} \text { served } \\
\text { in } 29.57-\mathrm{mL}(1-\mathrm{oz} .) \text { cup }]\end{array}$ & $\begin{array}{l}\text { Schnucks Heavy Whipping Cream } \\
\text { (Schnucks Market Inc.) }\end{array}$ & 10 \\
\hline Afterfeel & Dryness & $\begin{array}{l}\text { The sensation felt on the tongue } \\
\text { and sides of the mouth after the } \\
\text { sample has been expectorated }\end{array}$ & $\begin{array}{l}1.0 \mathrm{~g} \text { of tannic acid in } \\
1,000 \mathrm{~mL} \text { of water }\end{array}$ & $\begin{array}{l}\text { Tannic Acid (Sigma Chemical, } \\
\text { St. Louis, MO) }\end{array}$ & 11 \\
\hline
\end{tabular}

\footnotetext{
${ }^{1}$ References were rated iteratively over $5 \mathrm{~d}$ to generate a reference intensity and averaged over those $5 \mathrm{~d}$ of evaluation to give a mean value for the reference on a 16 -point category scale that ranged from 0 to 15.
} 
Table 3. Analysis of variance ( $F$-values) of 12 sensory attributes rated across 10 yogurt drinks

\begin{tabular}{|c|c|c|c|c|c|c|c|}
\hline \multirow[b]{2}{*}{ Modality } & \multirow[b]{2}{*}{ Attribute } & \multirow[b]{2}{*}{$\begin{array}{l}\text { Replication } \\
(\mathrm{R})\end{array}$} & \multirow[b]{2}{*}{$\begin{array}{l}\text { Panelist } \\
\text { (P) }\end{array}$} & \multirow[b]{2}{*}{$\begin{array}{l}\text { Sample } \\
\text { (S) }\end{array}$} & \multicolumn{3}{|c|}{ Interaction } \\
\hline & & & & & $\mathrm{R} \times \mathrm{P}$ & $\mathrm{R} \times \mathrm{S}$ & $\mathrm{P} \times \mathrm{S}$ \\
\hline \multirow[t]{3}{*}{ Aroma } & Vanilla & 1.94 & $5.02^{* * *}$ & 1.05 & 1.43 & 0.77 & 0.94 \\
\hline & Buttermilk & 1.32 & $8.70^{* * *}$ & $3.64^{* * *}$ & 1.27 & 0.54 & 1.02 \\
\hline & Butter & 1.90 & $15.99^{* * *}$ & $1.97^{*}$ & 1.77 & 0.56 & 1.06 \\
\hline Aroma-by-mouth & Vanilla & 1.77 & $13.33^{* * *}$ & 1.73 & 0.93 & 0.40 & 1.09 \\
\hline Taste and aftertaste & Cheese aftertaste & 0.77 & $26.16^{* * *}$ & 0.82 & $2.98^{* *}$ & 2.01 & 1.09 \\
\hline \multirow[t]{2}{*}{ Mouthfeel } & Chalky & $5.22 *$ & $5.68^{* * *}$ & $2.10^{*}$ & 1.56 & 0.65 & 0.65 \\
\hline & Viscous & 2.57 & $11.64^{* * *}$ & $3.91^{* * *}$ & $4.21^{* * *}$ & 0.71 & 0.96 \\
\hline Afterfeel & Dryness & 0.02 & $19.41^{* * *}$ & 1.00 & 0.95 & 1.90 & 0.98 \\
\hline
\end{tabular}

${ }^{*} P<0.05 ;{ }^{* *} P<0.01 ;{ }^{* * *} P<0.001$.

control that contained no prebiotics or probiotics $(P$ $<0.05)$. Beverages containing polydextrose at a high level and inulin at high and low levels were significantly more viscous than the control $(P<0.05)$. Increasing the concentration of prebiotics, especially inulin, has been shown to increase the viscosity and other mouthfeel characteristics of products (Guggisberg et al., 2009). Inulin yogurt drinks exhibited the highest sweet taste perception compared with the control $(P<0.05)$. Inulin, in particular short-chain inulin, has been shown to have a sweetness profile similar to that of saccharose and can significantly increase the sweetness level of a product (Villegas et al., 2010).

Probiotics have been shown in previous studies to not alter the sensory properties of yogurt (Atunes et al., 2005). However, as illustrated in Table 4, the addition of probiotics into the yogurt drinks that contained prebiotics at a high level did cause sensory attribute differences. In particular, when adding probiotics to the polydextrose and soluble corn fiber yogurt drinks, the chalkiness of the products became significantly greater than that of the control beverage $(P<0.05)$. Other specific product differences were found when adding probiotics. The polydextrose with probiotics yogurt drink had the lowest sweet clover honey intensity compared with the control $(P<0.05)$, and also had the highest sour buttermilk aroma compared with the other probiotic and prebiotic yogurt drinks $(P<0.05)$. The effect of polydextrose as a sweetener and its effect on increasing sweet aroma have been shown to be dependent on the product. In an antioxidant extract study, its effect at increasing sweetness was almost imperceptible compared with other sweeteners used in the study (Ares et al., 2009). The butter aroma intensity of the yogurt drink with soluble corn fiber at the high level became significantly lower $(P<0.05)$ when probiotics were incorporated in the beverage. Similarly, the addition of the same probiotics, Lb. acidophilus LA-5 and $B$. lactis $\mathrm{Bb}-12$, to drinkable yogurts made with goat milk reduced the intensity of several attributes

Table 4. Mean intensity ratings for significant attributes

\begin{tabular}{|c|c|c|c|c|c|c|c|}
\hline Sample $^{1}$ & \multicolumn{3}{|c|}{ Aroma attribute } & \multicolumn{2}{|c|}{ Taste attribute } & \multicolumn{2}{|c|}{ Mouthfeel attribute } \\
\hline PDX High & $8.08^{\mathrm{bc}}$ & $8.65^{\mathrm{bc}}$ & $7.54^{\mathrm{abcd}}$ & $8.81^{\mathrm{abcd}}$ & $8.19^{\mathrm{ab}}$ & $\begin{array}{l}0.01 \\
7.08^{\mathrm{cd}}\end{array}$ & $8.31^{\mathrm{bc}}$ \\
\hline PDX Low & $7.92^{\mathrm{bc}}$ & $8.77^{\mathrm{bc}}$ & $7.15^{\mathrm{cd}}$ & $8.54^{\text {bcd }}$ & $8.19^{\mathrm{ab}}$ & $7.15^{\mathrm{bcd}}$ & $8.04^{\text {bcde }}$ \\
\hline Inulin High & $7.88^{\mathrm{bc}}$ & $8.77^{\mathrm{bc}}$ & $7.65^{\text {abcd }}$ & $9.27^{\mathrm{ab}}$ & $7.88^{\mathrm{ab}}$ & $7.27^{\text {abcd }}$ & $8.69^{\mathrm{ab}}$ \\
\hline PDX + Pro & $7.5^{\mathrm{c}}$ & $9.73^{\mathrm{a}}$ & $7.77^{\mathrm{abc}}$ & $9.00^{\mathrm{abcd}}$ & $8.54^{\mathrm{a}}$ & $7.88^{\mathrm{a}}$ & $8.42^{\mathrm{abc}}$ \\
\hline Inulin + Pro & $7.88^{\mathrm{bc}}$ & $8.85^{\mathrm{bc}}$ & $7.38^{\mathrm{bcd}}$ & $9.31^{\mathrm{ab}}$ & $8.08^{\mathrm{ab}}$ & $7.42^{\mathrm{abcd}}$ & $7.85^{\text {cde }}$ \\
\hline $\mathrm{SCF}+$ Pro & $8.27^{\mathrm{bc}}$ & $8.23^{\mathrm{cd}}$ & $7.04^{\mathrm{d}}$ & $9.15^{\mathrm{abc}}$ & $7.58^{\mathrm{b}}$ & $7.65^{\mathrm{abc}}$ & $8.23^{\mathrm{bcd}}$ \\
\hline
\end{tabular}

${ }^{\mathrm{a} e}$ Means in the same column with the same letter are not significantly different $(P<0.05)$.

${ }^{1} \mathrm{PDX}=$ polydextrose; SCF $=$ soluble corn fiber; Pro = probiotics; high and low refer to levels of prebiotics added. 
Table 5. Survival (cfu/mL) of Bifidobacterium lactis Bb-12 and Lactobacillus acidophilus LA-5 in yogurt drinks during 30-d storage ${ }^{1}$

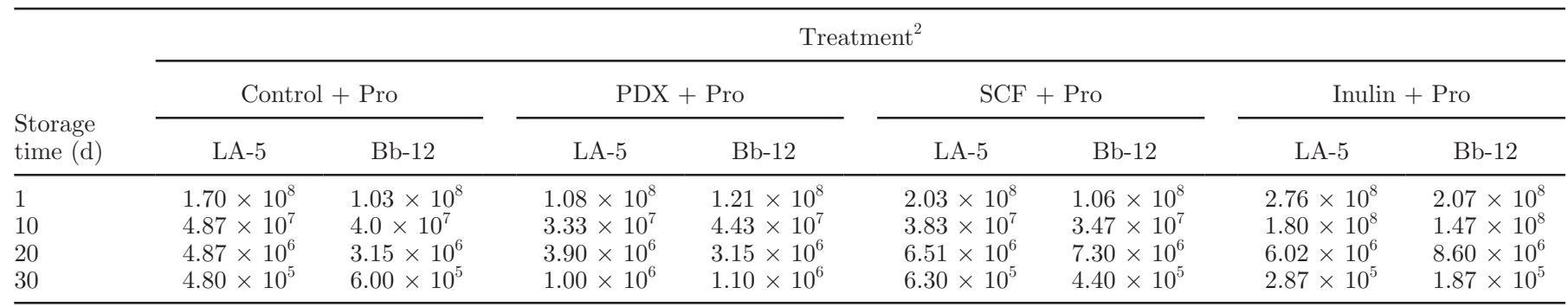

${ }^{1}$ Control treatment with no prebiotics/probiotics had zero growth for all $30 \mathrm{~d}$.

${ }^{2}$ Pro $=$ probiotics; $\mathrm{PDX}=$ polydextrose; SCF $=$ soluble corn fiber.

(Uysal-Pala et al., 2006). Causes for the differences in the sensory attributes in prebiotic yogurt drinks with probiotics are undetermined. However, it is known that probiotics have been shown to increase organic acid concentrations (lactic and acetic acid) and proteolysis during fermentation and subsequent storage of set yo- gurts (Donkor et al., 2007). The addition of prebiotics to a probiotic-containing yogurt also contributes to alterations in organic acid concentrations (lactic and acetic acids) and proteolysis during fermentation and subsequent storage (Donkor et al., 2007; Vasiljevic et al., 2007). Additionally, the effects on organic acid

Biplot (axes F1 and F2: $64.56 \%$ )

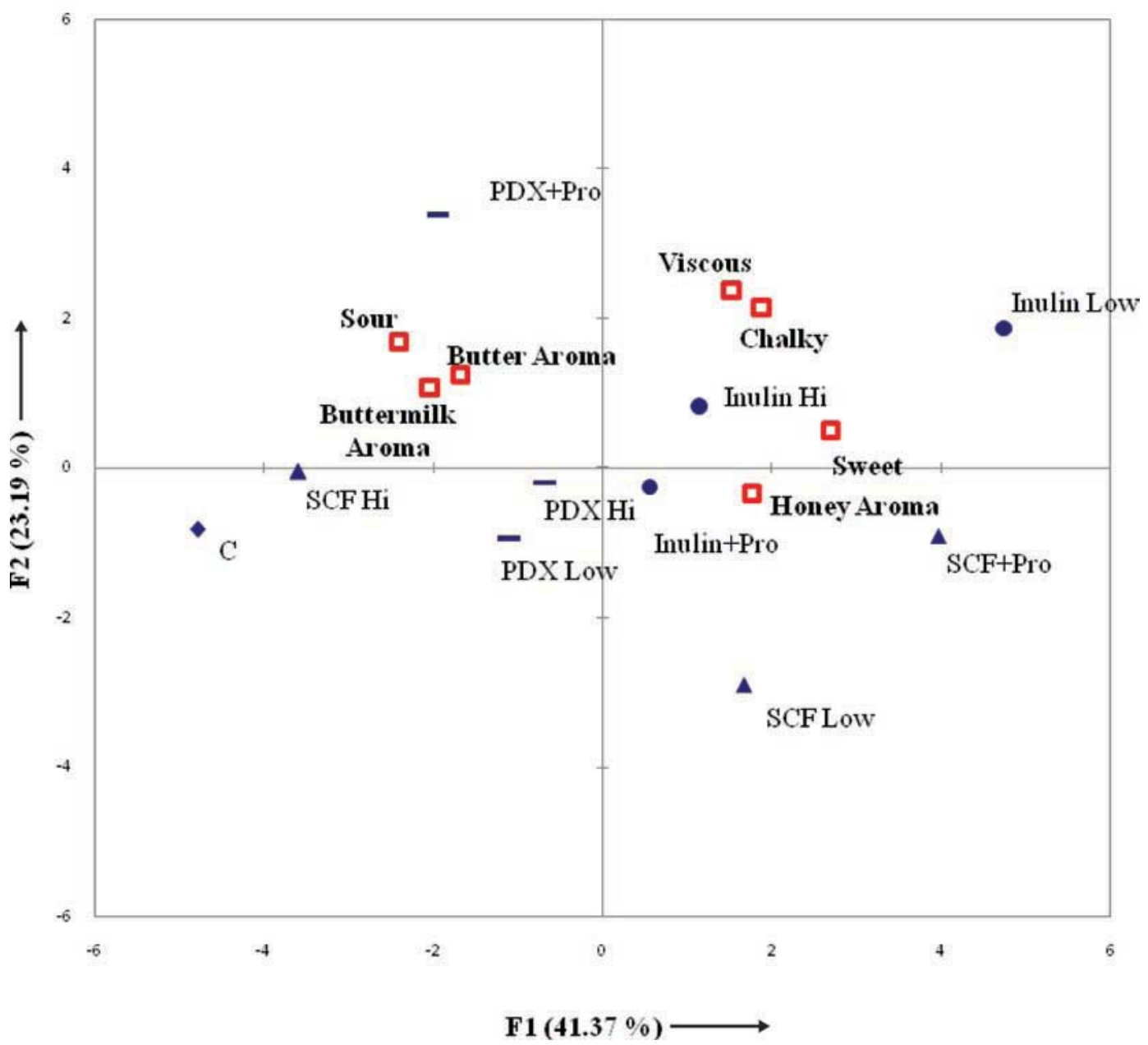

Figure 1. Principal component analysis biplot by the covariance matrix of the mean sensory ratings. $\square=$ attribute; $\boldsymbol{\Delta}$ (SCF) $=$ soluble corn fiber; $-(\mathrm{PDX})=$ polydextrose; - inulin; and $\bullet(\mathrm{C})=$ control; Pro = probiotics; Hi and Low $=$ high and low levels of prebiotics added, respectively. Color version available in the online PDF. 
production and proteolysis vary based on the specific prebiotic and probiotic added (Donkor et al., 2007; Vasiljevic et al., 2007).

The PCA biplot of the yogurt drinks (Figure 1) illustrates specific differences among the products. The biplot explains $64.6 \%$ of the total variation, with factor 1 on the $\mathrm{x}$-axis explaining $41.4 \%$ of the data and factor 2 on the y-axis explaining $23.2 \%$. Factor 1 was mostly accounted for by sweet and honey aroma versus sour, buttermilk aroma, and butter aroma based on the high loadings of these attributes on this factor. Factor 2 was characterized by the significant mouthfeel attributes, viscous and chalky. The yogurts with soluble corn fiber and inulin varied predominantly by factor 1 ; as we changed the amounts of prebiotics or added probiotics to these yogurt drinks, the sweetness versus sourness taste and aroma and butter aroma attributes were affected the most. If we altered the amount of polydextrose in the product, the sensory attributes most affected were the mouthfeel attributes, in particular, chalkiness. Previous studies have shown the capability of polydextrose to provide an increase in viscosity and mouthfeel perception in various foods (Mitchell, 2004). Solutions of polydextrose have been shown to have a higher viscosity than other sweetener solutions, which enables the prebiotic to provide desirable mouthfeel qualities important when reducing sugar and fats (Mitchell, 1996).

\section{Viability of Probiotic Cultures in Yogurt Drink}

Table 5 shows the survival of the probiotic strains B. lactis Bb-12 and Lb. acidophilus LA-5 during a 30-d refrigerated storage period. The control treatment with no prebiotics or probiotics demonstrated zero growth throughout the testing. There was an approximately 2 to $3-\log \operatorname{loss}$ in the total number of viable cells for both probiotics in all of the yogurt treatments during the 30 d. Several yogurt studies have determined similar results, showing that the survival of probiotic bacteria is often low in yogurt (Dave and Shah, 1997; Kailasapathy, 2006). The low $\mathrm{pH}$ of yogurt and postacidification of yogurt, further reducing the $\mathrm{pH}$, contribute to the low viability of probiotics (Kailasapathy, 2006).

All yogurt treatments maintained between $1.03 \times 10^{8}$ and $2.76 \times 10^{8} \mathrm{cfu} / \mathrm{mL}$ of each probiotic after $1 \mathrm{~d}$ of refrigerated storage. By d 10, all treatments decreased by approximately $70 \%$, except for the inulin treatment, which maintained a higher survival rate. Twenty days of refrigerated storage resulted in a decrease of approximately $85 \%$ of viable cells from d 10 in all of the yogurt treatments for both probiotics. At the end of the refrigerated storage period (d 30), B. lactis Bb-12 viable counts were $1.10 \times 10^{6}, 4.40 \times 10^{5}, 1.87 \times 10^{5}$, and
$6.00 \times 10^{5} \mathrm{cfu} / \mathrm{mL}$ for probiotic-containing yogurt with polydextrose, soluble corn fiber, inulin, and no prebiotic control, respectively. Lactobacillus acidophilus LA-5 viable counts were $1.00 \times 10^{6}, 6.30 \times 10^{5}, 2.87 \times 10^{5}$, and $4.80 \times 10^{5} \mathrm{cfu} / \mathrm{mL}$ for probiotic-containing yogurt with polydextrose, soluble corn fiber, inulin, and no prebiotic control, respectively. All yogurt drink treatments lost more than $99 \%$ of viable bacteria during the $30 \mathrm{~d}$. Variable results have been found when incorporating inulin in probiotic yogurt. Growth of L. acidophilus and L. rhamnosus have been shown to be enhanced with inulin (Sadek et al., 2004); however, similar to the results in this study, Lb. acidophilus LA-5 has been shown to not be stimulated by inulin in acidophilus-bifidus yogurts (Ozer et al., 2005). The minimal suggested level of viable probiotics at the time of consumption is approximately $10^{6} \mathrm{cfu} / \mathrm{mL}$ of product (Adhikari et al., 2003). Therefore, based on the results of the current study, only the polydextrose treatment would be an acceptable vehicle to deliver probiotic health effects at the end of the 30 -d yogurt drink storage.

Several methods to increase the survival of probiotics in yogurt have been recommended. Some of these include microencapsulation (Kailasapathy, 2006), a 2-step fermentation process with the probiotic fermentation first (Shah, 2000), and addition of ingredients known to increase viability such as cysteine, whey powder, and casein hydrolysates (Dave and Shah, 1998; Gomes et al., 1998; Adhikari et al., 2003). However, addition of such survival-enhancing ingredients may also affect the sensory characteristics of the yogurt, especially the texture (Kailasapathy, 2006). No specific viability differences were seen between the 2 probiotics in this study.

\section{CONCLUSIONS}

This study demonstrated the effect of adding healthpromoting ingredients into a yogurt drink system. The prebiotics inulin, soluble corn fiber, and polydextrose were shown to alter the sensory properties of the yogurt drink when incorporated at different levels. When probiotics were incorporated, additional sensory changes were identified. This study can be used as a reference for yogurt manufacturers looking to incorporate novel prebiotics and probiotics in their products for the sensory effects of the ingredients at relevant levels. The viability study revealed a 2- to 3-log decrease in survival of the probiotics, with or without prebiotics, after 30 d of refrigerated storage. It is recommended that additional methods or ingredients be used to ensure the viability of probiotics in the product because several studies now prove their low survival rate. Future research could include microencapsulating the probiotics to determine if their survival rate is increased in the 
novel prebiotic yogurt drink and to determine if the sensory characteristics of the drink become affected.

\section{REFERENCES}

Adhikari, K., A. Mustapha, and I. U. Grun. 2003. Survival and metabolic activity of microencapsulated Bifidobacterium longum in stirred yogurt. J. Food Sci. 68:275-280.

Ares, G., C. Barreiro, R. Deliza, and A. Gámbaro. 2009. Alternatives to reduce the bitterness, astringency and characteristic flavor of antioxidant extracts. Food Res. Int. 42:871-878.

Atunes, A. E., T. F. Cazetto, and H. M. Bolini. 2005. Viability of probiotic micro-organisms during storage, postacidification and sensory analysis of fat-free yogurts with added whey protein concentrate. Int. J. Dairy Technol. 58:169-173.

Beer, M., E. Arrigoni, D. Uhlmann, D. Wechsler, and R. Amado. 1991. Stability of polydextrose solutions to heat treatment and storage under acidic conditions. Lebensm. Wiss. Technol. 24:245-251.

Chandan, R. C., C. H. White, A. Kilara, and Y. H. Hui. 2006. Manufacturing Yogurt and Fermented Milks. Blackwell Publishing, Ames, IA.

Collins, M. D., and G. R. Gibson. 1999. Probiotics, prebiotics, and synbiotics: approaches for modulating the microbial ecology of the gut. Am. J. Clin. Nutr. 69:1052S-1057S.

Dave, R. I., and N. P. Shah. 1997. Viability of yogurt and probiotic bacteria in yogurts made from commercial starter cultures. Int. Dairy J. 7:31-41.

Dave, R. I., and N. P. Shah. 1998. Ingredient supplementation effects on viability of probiotic bacteria in yogurt. J. Dairy Sci. 81:2804-2816.

Donkor, O. N., S. L. I. Nilmini, P. Stolic, T. Vasiljevic, and N. P. Shah. 2007. Survival and activity of selected probiotic organisms in settype yogurt during cold storage. Int. Dairy J. 17:657-665.

Eder, R. 2003. Drinkable yogurt beats the bagel. Drug Store News $25: 42$.

FAO/WHO. 2001. Health and nutritional properties of probiotics in food including powder milk with live lactic acid bacteria. Report of a Joint FAO/WHO Expert Consultation on Evaluation of Health and Nutritional Properties of Probiotics in Food Including Powder Milk with Live Lactic Acid Bacteria. WHO, Geneva, Switzerland.

FDA. 2008. Food Labeling Guide: Appendix B: Additional Requirements for Nutrient Content Claims. http://www.cfsan.fda. gov/ dms/2lg-xb.html Accessed Feb., 2008.

Fonden, R., B. Grenov, R. Reniero, M. Saxelin, and S. E. Birkeland. 2000. Industrial panel statements: Technological aspect. 19:843850 in Functional foods for EU-Health in 2000, 4th Workshop, FAIR CT96-1028. M. Alander and T. Mattila-Sandholm, ed. PROBDEMO, VTT Symposium, Rovaniemi, Finland.

Gibson, G. R., and M. B. Roberfroid. 1995. Dietary modulation of the human colonic microbiota: Introducing the concept of prebiotics. J. Nutr. 125:1401-1412.

Gomes, A. M. P., F. X. Malcata, and F. A. M. Klaver. 1998. Growth enhancement of Bifidobacterium lactis Bo and Lactobacillus acidophilus Ki by milk hydrolyzates. J. Dairy Sci. 81:2817-2825.

Guggisberg, D., J. Cuthbert-Steven, P. Piccinali, U. Bütikofer, and P. Eberhard. 2009. Rheological, microstructural and sensory charac- terization of low-fat and whole milk set yogurt as influenced by inulin addition. Int. Dairy J. 19:107-115.

Hekmat, S., and G. Reid. 2006. Sensory properties of probiotic yogurt is comparable to standard yogurt. Nutr. Res. Rev. 26:163-166.

International Scientific Association for Probiotics and Prebiotics (ISAPP). 2009. Prebiotics: A consumer guide for making smart choices. http://www.isapp.net/docs/Consumer_Guidelines-prebiotic.pdf.

Kailasapathy, K. 2006. Survival of free and encapsulated probiotic bacteria and their effect on the sensory properties of yogurt. Lebensm. Wiss. Technol. 39:1221-1227.

Mitchell, H. L. 1996. The role of bulking agent polydextrose in fat replacement. Pages 237-238 in Handbook of Fat Replacers. CRC Press, Boca Raton, FL.

Mitchell, H. L. 2004. Capture the opportunity: Sustained fermentation with litesse, polydextrose and lactitol - The health benefits. Innov. Food Technol. 13:24-26.

Mojet, J., E. Christ Hazelhof, and J. Heidema. 2001. Taste perception with age: Generic or specific losses in threshold sensitivity to the five basic tastes? Chem. Senses 26:845-860.

Ozer, D., S. Akin, and B. Ozer. 2005. Effect of inulin and lactulose on survival of Lactobacillus acidophilus LA-5 and Bifidobacterium bifidum Bb-02 in acidophilus-bifidus yogurt. Food Sci. Technol. Int. $11: 19-24$.

Sadek, Z., K. El-Shafei, and H. A. Murad. 2004. Utilization of xanthan gum and inulin as prebiotics for lactic acid bacteria. Pages 269-283 in 9th Egyptian Conference for Dairy Science and Technology, Cairo, Egypt. Egyptian Society of Dairy Science, Cairo.

Saint-Eve, A., C. Levy, N. Martin, and I. Souchon. 2006. Influence of proteins on the perception of flavored stirred yogurts. J. Dairy Sci. 89:922-933.

Sanders, M., G. Gibson, H. Gill, and F. Guarner. 2007. Probiotics: Their potential to impact human health. Council for Agricultural Science and Technology (CAST) Issue Paper, 36. CAST, Ames, IA.

Shah, N. P. 2000. Probiotic bacteria: Selective enumeration and survival in dairy foods. J. Dairy Sci. 83:894-907.

Tamime, A. Y., and R. K. Robinson. 1985. Yogurt: Science and Technology. Woodhead Publishing Ltd., Cambridge, UK.

Thompson, J. L., K. Lopetcharat, and M. A. Drake. 2007. Preferences for commercial strawberry drinkable yogurts among African American, Caucasian, and Hispanic consumers in the United States. J. Dairy Sci. 90:4974-4987.

Uysal-Pala, C., Y. Karagul-Yuceer, A. Pala, and T. Savas. 2006. Sensory properties of drinkable yogurt made from milk of different goat breeds. J. Sens. Stud. 21:520-533.

Vasiljevic, T., T. Kealy, and V. K. Mishra. 2007. Effects of $\beta$-glucan addition to a probiotic containing yogurt. J. Food Sci. 72:C405C411.

Villegas, B., A. Tárrega, I. Carbonell, and E. Costell. 2010. Optimizing acceptability of new prebiotic low-fat milk beverages. Food Qual. Prefer. 21:234-242.

Zhao, L., S. V. Kirkmeyer, and B. J. Tepper. 2003. A paper screening test to assess genetic taste sensitivity to 6 -n-propylthiouracil. Physiol. Behav. 78:625-633. 